\title{
Stated Preferences in Non-Small-Cell Lung Cancer: A Discrete Choice Experiment
}

\section{Isandra Meirelles (D) Carlos Magliano (1)*}

Health Technology Assessment Unit, Instituto Nacional de Cardiologia, Rio de Janeiro, Rio de Janeiro, Brazil

*These authors contributed equally to this work
Correspondence: Isandra Meirelles Email isandrameirelles@gmail.com
Introduction: The different alternatives for non-small-cell lung cancer (NSCLC) treatment can increase survival but cause important adverse events. Therefore, patients' preference can play a critical role in decision-making. Among stated preference methods, discrete choice experiment (DCE) is the most applied in health care to elicit preferences. This research aims to elicit patients' preference evaluating the trade-off between the risks (adverse events) and benefits (survival) of systemic treatments, from the perspective of Brazilian patients with locally advanced, metastatic or recurrent NSCLC.

Methods: A DCE was performed following the steps of attributes selection; construction of tasks and respondents' preference elicitation. Patients chose between 2 hypothetical treatments described by the attributes tiredness, hair loss, skin rash, hospitalization, administration mode and survival. A paper-and-pencil survey method was used to elicit the answers from the participants. The statistical data analysis used a mixed logit model to predict the relative importance of the attributes.

Results: Most of the 65 patients interviewed were men $(53.8 \%)$, mean age of 65 (95\% confidence interval [CI]: 63-67) years and lung cancer stage IV (67.7\%). Except for hospitalization and administration mode, the attributes coefficients were statistically significant $(\mathrm{p}<0.005)$ for patients' preferences. Patients would require a minimum survival gain of 11.72 (CI: 10.28-4.22) months and 19.72 (CI: 17.31-7.09) months to accept a treatment that causes severe tiredness and severe skin rash, respectively. The market share of the treatments was calculated according to the DCE aggregate-level estimation, considering the impact of each treatment's side effects. Paclitaxel plus carboplatin had an estimated market share of $31 \%$, followed by gefitinib (27\%), erlotinib (24\%) and docetaxel $(18 \%)$.

Conclusion: In general, less than a year of survival gain would not suffice for the appearance of severe skin rash or tiredness.

Keywords: non-small-cell lung cancer, patient preference

\section{Introduction}

Lung cancer is the most prevalent in the world and the major cause of cancer death worldwide. In Brazil, it was estimated by the Instituto Nacional de Câncer, 30.000 new cases for each year of the 2020-2022 biennium. These values correspond to an estimated risk of 16.99 new cases for every 100.000 men and 11.56 for every 100.000 women. ${ }^{1}$

The most common histological subtype is non-small-cell lung cancer (NSCLC) representing $85 \%$ of cases. ${ }^{1}$ In Brazil, most of the patients are diagnosed in advanced stages.

In a scenario of patients with locally advanced, metastatic or recurrent disease, palliative chemotherapy regimens based on platinum agents, taxanes, gemcitabine, 
vinorelbine, pemetrexed and etoposide, are offered to patients who do not present the most recurrent molecular alterations found in NSCLC, which are detected in Epidermal Growth Factor Receptor (EGFR), Anaplastic Lymphoma Kinase (ALK), ROS Proto-Oncogene 1 (ROS1) and high expression of Programmed Death Ligand 1 (PD-L1). Patients with these molecular changes receive isolated target therapies or in combination with chemotherapy. ${ }^{2}$

Each one of these alternatives, which is associated either with clinically important adverse events, or different dose schedules or administration methods, can increase the survival rates. For that reason, the inclusion of patients' preference in the treatment choice can improve treatment adherence and lead to better results. ${ }^{3}$

However, data of Brazilian patients' preferences with NSCLC can not be applied in decision-making for starting a new treatment because they are not available.

The conjoint analysis ensures that patients are presented with specific risk information per subgroup. Data of quality life scales are difficult to translate into concrete variables of what patients value more - always in relation to the results of treatment. ${ }^{4}$

The objective of this study is to estimate preferences from patients with locally advanced, metastatic or recurrent NSCLC eliciting the amount of side effects they are willing to accept to prolong survival. It was considered the tradeoffs between risks (adverse events) and benefits (survival gain) related to lung cancer treatments in a population in outpatient treatment at a public health service.

\section{Methods}

\section{Discrete Choice Experiment}

Discrete choice experiment (DCE) is a choice-based conjoint analysis used to quantify patients' preferences and evaluate decisions that they are willing to make between different aspects or attributes of health technologies. ${ }^{3}$ It is based on the assumption that any good can be described by selected attributes and their respective levels, and when individuals have the opportunity to choose, they would make the best choice comparing these attributes and levels. ${ }^{3}$

Each participant was presented with 12 hypothetical choice scenarios. Each set of choices consisted of two alternatives described by attributes. Alternatives were created
Table I Selected Attributes and Levels for Hypothetical Scenarios About Lung Cancer Treatment

\begin{tabular}{|c|c|c|}
\hline Attributes & Description & Levels \\
\hline Tiredness & $\begin{array}{l}\text { Some treatments may } \\
\text { make you weak or } \\
\text { tired, and this may limit } \\
\text { your daily activities }\end{array}$ & $\begin{array}{l}\text { (1) Mild (does not limit } \\
\text { daily activities) } \\
\text { (2) Moderate (limits } \\
\text { some daily activities) } \\
\text { (3) Severe (limits } \\
\text { activities such as } \\
\text { bathing or dressing } \\
\text { alone) }\end{array}$ \\
\hline Hair loss & $\begin{array}{l}\text { Some treatments may } \\
\text { cause hair loss }\end{array}$ & $\begin{array}{l}\text { (1) No hair loss } \\
\text { (2) } 15 \text { out of } 100 \\
\text { people have hair loss } \\
\text { (15\%) } \\
\text { (3) } 40 \text { out of } 100 \\
\text { people have hair loss } \\
(40 \%)\end{array}$ \\
\hline Skin rash & $\begin{array}{l}\text { Some treatments can } \\
\text { cause rashes (eg, } \\
\text { blisters with pus, red } \\
\text { swollen plaques, and } \\
\text { itching). Antibiotics may } \\
\text { be necessary }\end{array}$ & $\begin{array}{l}\text { (I) No skin lesions } \\
\text { (2) Moderate (up to } \\
30 \% \text { of body) } \\
\text { (3) Severe (more than } \\
30 \% \text { of the body or } \\
\text { antibiotics are } \\
\text { required) }\end{array}$ \\
\hline Hospitalization & $\begin{array}{l}\text { There is a risk of } \\
\text { hospitalization related } \\
\text { to some side effects }\end{array}$ & $\begin{array}{l}\text { (1) No hospitalization } \\
\text { (2) } 5 \text { out of } 100 \text { people } \\
\text { are hospitalized (5\%) } \\
\text { (3) } 15 \text { out of } 100 \\
\text { people are hospitalized } \\
\text { (15\%) }\end{array}$ \\
\hline $\begin{array}{l}\text { Administration } \\
\text { mode }\end{array}$ & $\begin{array}{l}\text { Medicines may be } \\
\text { administered orally or } \\
\text { intravenously. Orally, } \\
\text { you can take the pills at } \\
\text { home. If intravenously } \\
\text { you have to go to the } \\
\text { hospital, where you will } \\
\text { receive the medication } \\
\text { and stay there for at } \\
\text { least } 2 \text { hours }\end{array}$ & $\begin{array}{l}\text { (I) Intravenous (Ix } \\
\text { every } 3 \text { weeks) } \\
\text { (2) I tablet per day }\end{array}$ \\
\hline Survival & $\begin{array}{l}\text { Survival reflects the } \\
\text { expectation of living } \\
\text { longer. Different } \\
\text { treatments may have } \\
\text { different survival } \\
\text { expectations }\end{array}$ & $\begin{array}{l}\text { (I) } 4 \text { months } \\
\text { (2) } 8 \text { months } \\
\text { (3) } 12 \text { months }\end{array}$ \\
\hline
\end{tabular}


with the variation of attributes levels according to a statistical model. ${ }^{3}$ For each choice set, participants were asked to choose which alternative they preferred.

\section{Selection of Attributes and Levels}

In order to establish which attributes and respective levels would integrate the experiment, we conducted a preparatory study divided into four stages: literature review, interviews with patients, meeting with experts and consensus meeting.

Attributes and levels were identified on a systematic review, aiming to list all possible outcomes and characteristics related to available treatments and the disease. Following good practices, the list of potential attributes identified in literature was discussed in two focus groups with patients and one with clinical experts. ${ }^{3}$ The attributes selected by patients as the most important were revised and discussed by the clinical experts to reach a consensus on what would be the attributes presented in the scenarios.

Attributes were assigned with two or three levels describing NSCLC treatment alternatives. The selected attributes in the survey were tiredness, hair loss, skin rash, hospitalization, administration mode and survival (Table 1).

The description of each attribute was explained to participants before the beginning of the choice tasks, so that they could make choices considering the expected understanding of attributes and their levels.

\section{Construction of the Experimental Design}

The combination of attributes and levels would result in a high number of scenarios and it would disengage the participants. ${ }^{3}$ To avoid participant burden, we used a blocking approach. It was applied a fractional factorial design, using NGene software to generate optimal scenarios.

The selected design consisted of 36 choice sets divided into three equal sized blocks of 12 paired choices. Each participant answered 12 choice tasks.

To guarantee the design optimization, the properties of orthogonality and balance were ensured, that is, the independent variation of attributes and levels between the choice scenarios, and the occurrence of each attribute and level at the same number of times in the scenarios. Applying the patients hypothetical choices to a conditional logistic model, we have the coefficients that represent the relative weight of each attribute level. ${ }^{5}$

Treatment alternatives had no labels. It was used visual aids and no opt-out options were included. An example survey is presented in Figure 1.

\begin{tabular}{|c|c|c|}
\hline Attributes & Treatment A & Treatment B \\
\hline Tiredness & Mild & Mild \\
\hline Hair lass & 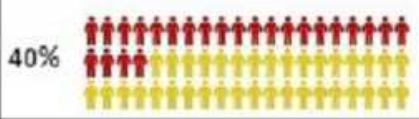 & 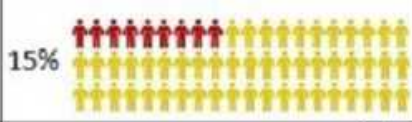 \\
\hline Skin rash & No skin lesions & Moderate \\
\hline Hospitalization & 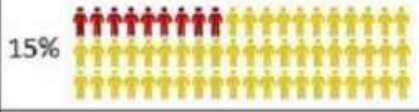 & No hospitalization \\
\hline Administration mode & 1 tablet per day & $\begin{array}{l}\text { Intravenous } \\
\text { (1x every } 3 \text { weeks) }\end{array}$ \\
\hline Survival & 12 months & 4 months \\
\hline $\begin{array}{l}\text { Which treatment would } \\
\text { you choose? }\end{array}$ & (1) & (1) \\
\hline
\end{tabular}

Figure I Example choice task. 


\section{Study Population, Sample Size and Data Collection}

A survey was conducted from March to October 2019 in a public oncology hospital in Rio de Janeiro, Brazil. The sample size calculation was performed based on Orme's rule. The minimum size is estimated by multiplying the factor 500 by the number of option levels with the highest number of levels (three); dividing the result by the number of scenarios that each patient will answer ${ }^{12}$ and by the number of options present in each scenario (two). ${ }^{6}$ Thus, the sample size was estimated at $(500 \times 3) /(12 \times 2), 63$ participants. The inclusion criteria were: 1) Subjects over 18 years old; 2) subjects who had experienced at least one chemotherapy or target therapy regimen for locally advanced, metastatic or recurrent NSCLC, 3) who considered themselves able to understand the hypothetical scenarios and 4) agreed to sign the informed consent form.

A pilot study was performed with 17 patients with the same characteristics of the target population to test the clarity of the questionnaire and identify possible difficulties of project execution. ${ }^{3}$ After a detailed explanation about the questionnaire and the purpose of study, participants were invited to respond to a 30 minutes structured interview.

The study was approved by the Ethics Committee of Instituto Nacional de Câncer José Alencar Gomes da Silva (CAAE 94708918.4.3001.5274 - November 28, 2018). Patients received copies of written informed consent and were informed about their right to refuse. This study was conducted in accordance with the Declaration of Helsinki.

Patients were recruited using the institutional database by convenience sampling. They completed a selfadministered questionnaire on sociodemographic (age, gender, marital status, number of children, income, smoking, educational level, race) and clinical characteristics (stage of disease, previous treatment, adverse events experienced, time of NSCLC diagnosis, and comorbidities). Complementary information was collected in medical charts.

\section{Maximum Acceptable Risk}

The Maximum Acceptable Risk (MAR) is the ratio of any two coefficients. From this calculation, it is possible to estimate the average magnitude of risk that patients are willing to accept in one of the attributes in exchange for achieving a gain in another attribute, ie, the trade-offs between attributes. ${ }^{7}$
In this case study, the aforementioned calculation validates the research question on the amount of risk that patients are willing to accept in exchange for gaining months of survival, in the case of adverse events.

\section{Statistical Analysis}

A conditional logit model was used to predict the probabilities of choosing an alternative and the relationship between the attributes and levels presented in the choice scenarios. Data analysis was performed using R software. For the parameters' estimation a p-value $<0.05$ was considered statistically significant.

\section{Results}

Sixty-five patients were interviewed. The main clinical and sociodemographic characteristics are presented in Table 2. Most of the participants were men (53.8\%) with a mean

Table 2 Main Characteristics of Study Sample

\begin{tabular}{|c|c|}
\hline & $n=65$ \\
\hline Age - Years (range) & $65.5(35-84)$ \\
\hline \multicolumn{2}{|l|}{ Gender - N (\%) } \\
\hline Male & $35(53.8)$ \\
\hline Female & $30(46.2)$ \\
\hline \multicolumn{2}{|l|}{ Education level - No (\%) } \\
\hline Less than high school & $34(52.3)$ \\
\hline High school & $19(29.2)$ \\
\hline Bachelor' degree & $12(18.4)$ \\
\hline \multicolumn{2}{|l|}{ Marital status } \\
\hline Married & $37(57)$ \\
\hline Single & $15(23.1)$ \\
\hline Other & I3 (20) \\
\hline Monthly Income - mean (SD)* & U\$ $479.25(626.18)$ \\
\hline \multicolumn{2}{|l|}{ Cancer stage - No (\%) } \\
\hline II & $3(4.6)$ \\
\hline III & $18(27.7)$ \\
\hline IV & $44(67.7)$ \\
\hline \multicolumn{2}{|l|}{ Treatment received - No (\%) } \\
\hline Conventional chemotherapy & $57(87.7)$ \\
\hline Target therapy & $8(12.3)$ \\
\hline Radiotherapy & $28(43 . I)$ \\
\hline Surgery & $8(12.3)$ \\
\hline
\end{tabular}

Notes: The target therapies used were erlotinib and gefitinib. *Monthly average income in Brazil $=\$ 469,97$.

Abbreviations: $\mathrm{N}$, number of participants; SD, standard deviation. 
Table 3 Estimated Relative Preference Weights

\begin{tabular}{|l|c|c|c|}
\hline Attributes & Coefficients & $\begin{array}{c}\text { Standard } \\
\text { Error }\end{array}$ & $\begin{array}{c}\text { Rob.t. } \\
\text { ratio }\end{array}$ \\
\hline Severe tiredness & -0.0633 & 0.1423 & -4.45 \\
Moderate tiredness & -0.0538 & 0.1417 & -0.38 \\
Hair loss & -0.0135 & 0.0034 & -3.97 \\
Moderate skin rash & -0.4497 & 0.1144 & -3.93 \\
Severe skin rash & -1.0652 & 0.1577 & -6.75 \\
Hospitalization & -0.0133 & 0.0099 & -1.34 \\
Administration mode & -0.1913 & 0.1127 & -1.70 \\
Survival & 0.054 & 0.0226 & 2.39 \\
\hline
\end{tabular}

age of 65 years. Most of the patients were in lung cancer stage IV and were treated in first and second lines of palliative chemotherapy based on paclitaxel plus carboplatin (54\%), gemcitabine (12\%) and docetaxel (12\%). The target therapy used by patients in this study were the EGFR inhibitors erlotinib and gefitinib.

The results of the analysis showed that coefficients were statistically significant for nearly all attributes $(\mathrm{p}<0.05)$, meaning that they played a significant role in patients' decisions, except for hospitalization and administration mode. The higher coefficients represent a greater influence on decision-making. Consequently, the attributes skin rash, tiredness and survival were more relevant for patients' choices. The negative coefficients indicate that patients considered the attributes to be undesirable (Table 3).

In Random Utility Theory, the systematic component of utility can be explained by the attribute levels of the alternative and the beta coefficients in this function represent the preference weights for each attribute level that are estimated by the model (8).

Table 4 refers to the MAR. The reference for the calculation of MAR was the coefficient of the attribute survival, considering survival time in months. It can be interpreted as the minimum survival gain, in months, which a patient would require to prefer a treatment related to a certain adverse event. For example, if a therapeutic option causes severe tiredness, it would be preferable over another that does not cause the same adverse event, only if it offered a survival gain greater than 11.72 months (Table 4).

Table 5 refers to forecasting market share. Considering that the alternative with the highest utility is chosen, choice probabilities can be estimated based on the utilities of options. The sum of all attribute level utilities presented in a treatment option compared to the sum of all attribute level utilities presented in another treatment option will directly impact in the probability of one of them being chosen (the probability of an alternative being chosen or its market share can be estimated by the exponential of the alternative utility in relation to the sum of exponential of utilities from all options). ${ }^{9}$

The utilities and market share for the first and second lines treatments more frequently used by the interviewed patients were calculated from the application of estimated relative preferences for each attribute that were significant for patients' choices, and the frequency of adverse events found in literature, ${ }^{10-12}$ in the utility equation.

For example, treatment with paclitaxel plus carboplatin gives a medium overall survival of 17.3 months, with a $58 \%$ probability of hair loss, $2 \%$ of severe tiredness, $42 \%$ of moderate tiredness, $1 \%$ of severe rash and $22 \%$ of moderate rash, producing 0.78 QALY. Considering these parameters, $31 \%$ of interviewed patients would prefer to be treated with paclitaxel plus carboplatin, while others would prefer to be treated with the other alternatives (Table 5).

Table 4 Estimated Relative Preferences, MAR and OR

\begin{tabular}{|l|c|c|c|}
\hline Attributes & Coefficients (CI 95\%) & MAR (CI 95\%) & OR (CI 95\%) \\
\hline Severe tiredness & $-0.0633(-0.9119 ;-0.3540)$ & $-11.72(-10.28 ;-4.22)$ & $0.531(0.402 ; 0.702)$ \\
Moderate tiredness & $-0.0538(0.3831 ;-0.1723)$ & $-0.99(-7.09 ;-0.27)$ & $0.948(0.682 ; 1.188)$ \\
Hair loss & $-0.0135(-0.0331 ;-0.0198)$ & $-0.25(-0.22 ;-0.09)$ & $0.986(0.967 ; 0.980)$ \\
Moderate skin rash & $-0.4497(-1.106 ;-0.657)$ & $-8.32(-20.47 ;-12.17)$ & $0.638(0.331 ; 0.518)$ \\
Severe skin rash & $-1.0652(-2.3969 ;-1.7787)$ & $-19.72(-17.31 ;-7.09)$ & $0.345(0.091 ; 0.168)$ \\
Hospitalization & $-0.0133(-0.0067 ;-0.0455)$ & $-0.2463(-0.2161 ;-0.0885)$ & $0.987(0.955 ; 0.993)$ \\
Administration mode & $-0.1913(-0.0455 ;-0.0067)$ & $-3.542(-3.108 ;-1.274)$ & $0.826(0.55 I ; 0.857)$ \\
Survival & $0.054(0.0615 ; 0.1501)$ & 1.00 & $1.055(1.063 ; 1.162)$ \\
\hline
\end{tabular}

Abbreviations: $\mathrm{Cl}$, confidence intervals; MAR, maximum acceptable risk; OR, odds ratio. 


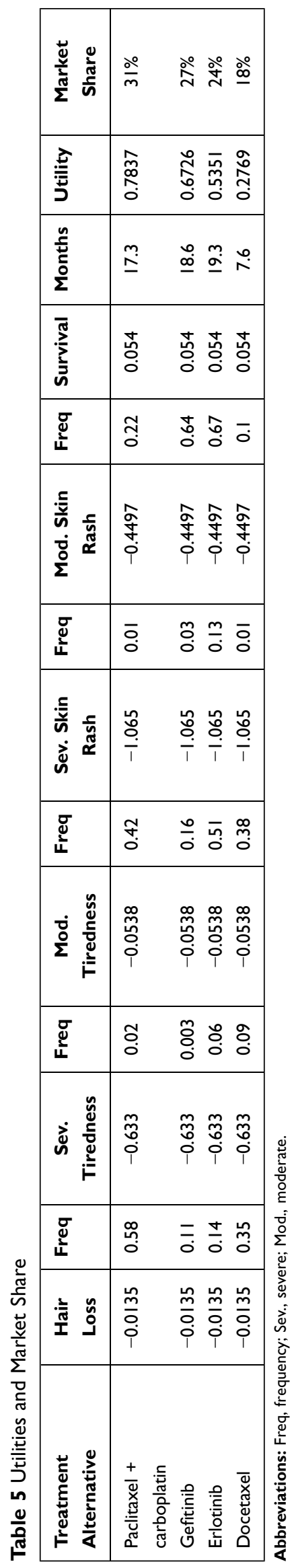

\section{Discussion}

In the current study, we applied a DCE to evaluate patients' preferences and trade-offs between risks and benefits included in decision-making about NSCLC treatment. To our knowledge, this is the first study to evaluate these preferences in Brazil.

The results showed that in addition to survival, the toxicity is an important characteristic to be considered by patients when choosing a treatment. The reason being is that the patients would consider accepting a treatment that causes severe tiredness if the minimum survival benefit would be prolonged 11.72 months, and a treatment that causes severe skin rash for 19.72 months, respectively.

These findings are consistent with some earlier studies. In the Mülbacher et al study, they identified that patients would require 7 months of progression free survival (PFS) with disease symptom control to accept tiredness as a consequence of NSCLC treatment. ${ }^{13}$ Bridges et al did a DCE to elicit NSCLC patients' preferences for treatment with EGFR inhibitors. In this study, patients would only be willing to accept a drug related to severe skin rash or severe tiredness, if there was a minimum benefit of 9.2 and 8.9 months of PFS, respectively. ${ }^{14}$ Although PFS gain is not the same as overall survival gain, in our study we identified that patients require an expressive survival gain to accept the adverse events related to the treatment options.

This study has some limitations. Subgroup analyses were not performed due to the small sample size. The patients who composed the study sample were selected by a convenience approach at a Brazilian public hospital, which may compromise the generalization of the results for the general population.

A key component to shared decision-making (SDM) is acknowledging patient preference and values. The objectives of SDM are achieved when the trade-offs between risks and benefits of treatment options are discussed with the patients. ${ }^{15}$

The results demonstrate the importance of including toxicity in the treatment plan, from the perspective of patients and physicians, the role of preference elicitation and preference clarification exercises, allowing SDM.

\section{Conclusion}

Following the methodology discussed, literature review, patients and specialists' questionnaire and attributes selection along with the levels related to the choice of treatment, it was then possible to estimate the impact of 
adverse events caused by treatments according to patients' perspectives.

New drugs, with a better safety profile which minimises adverse events such as skin rash, hair loss and tiredness, have a higher potential to be accepted by patients regardless of the administration method.

In general, less than a year of survival gain would not suffice for the appearance of unwanted attributes like severe skin rash or tiredness.

The utility equation and the estimated relative preferences for the main attributes as presented in this study, will allow future researchers to estimate the potential market share of a new drug for non-small-cell lung cancer treatment.

\section{Acknowledgments}

We would like to thank the members of Health Technology Assessment Groups from Instituto Nacional de Cardiologia and from Instituto Nacional de Câncer, as well as, Instituto Nacional de Câncer staff for research support.

\section{Funding}

There is no funding to report.

\section{Disclosure}

The abstract of this paper was presented at the Virtual ISPOR Conference 2020 as a poster presentation with interim findings. The authors report no conflicts of interest in this work.

\section{References}

1. Instituto Nacional de Cancer. Estimativa 2020: incidência de câncer no Brasil [Internet]; 2020. Available from: inca.gov.br/publicacoes/livros/ estimativa-2020-incidencia-de-cancer-no-brasil. Accessed April 1, 2020.

2. Bironzo P, Di Maio M. A review of guidelines for lung cancer. $J$ Thorac Dis. 2018;10(Suppl 13):S1556-63. doi:10.21037 jtd.2018.03.54

Patient Preference and Adherence

\section{Publish your work in this journal}

Patient Preference and Adherence is an international, peer-reviewed, open access journal that focusing on the growing importance of patient preference and adherence throughout the therapeutic continuum. Patient satisfaction, acceptability, quality of life, compliance, persistence and their role in developing new therapeutic modalities and compounds to optimize clinical outcomes for existing disease
3. Bridges JFP, Hauber AB, Marshall D, et al. Conjoint analysis applications in health-a checklist: a report of the ISPOR good research practices for conjoint analysis task force. Value Health. 2011;14 (4):403-413. doi:10.1016/j.jval.2010.11.013

4. Ryan M. Discrete choice experiments in health care. BMJ. 2004;328 (7436):360-361. doi:10.1136/bmj.328.7436.360

5. López-Bastida J, Ramos-Goñi JM, Aranda-Reneo I, Taruscio D, Magrelli A, Kanavos P. Using a stated preference discrete choice experiment to assess societal value from the perspective of patients with rare diseases in Italy. Orphanet $J$ Rare Dis. 2019;14(1):154. doi:10.1186/s13023-019-1126-1

6. Horne M, Jaccard M, Tiedemann K. Improving behavioral realism in hybrid energy-economy models using discrete choice studies of personal transportation decisions. Energy Economics. 2005;27(1):59-77.

7. Mehdi N, Gagne Joshua J, Choudhry Niteesh K, Polinski Jennifer M, Jerry A, Schneeweiss Sebastian S. Patients' preferences in anticoagulant therapy. Circ Cardiovasc Qual Outcomes. 2014;7(6):912-919. doi:10.1161/CIRCOUTCOMES.114.001013

8. Hauber AB, González JM, Groothuis-Oudshoorn CGM, et al. Statistical methods for the analysis of discrete choice experiments: a report of the ISPOR conjoint analysis good research practices task force. Value Health. 2016;19(4):300-315. doi:10.1016/j. jval.2016.04.004

9. Ryan M, Gerard K, Amaya-Amaya M. Using discrete choice experiments to value health and health care. 2008;11.

10. Mok TS, Wu Y-L, Thongprasert $\mathrm{S}$, et al. Gefitinib or carboplatin-paclitaxel in pulmonary adenocarcinoma. $N$ Engl $J$ Med. 2009;361(10):947-957. doi:10.1056/NEJMoa0810699

11. Kim ES, Hirsh V, Mok T, et al. Gefitinib versus docetaxel in previously treated non-small-cell lung cancer (INTEREST): a randomised Phase III trial. Lancet. 2008;372(9652):1809-1818. doi:10.1016/S0140-6736(08)61758-4

12. Rosell R, Carcereny E, Gervais R, et al. Erlotinib versus standard chemotherapy as first-line treatment for European patients with advanced EGFR mutation-positive non-small-cell lung cancer (EURTAC): a multicentre, open-label, randomised Phase 3 trial. Lancet Oncol. 2012;13(3):239-246. doi:10.1016/S1470-2045(11) 70393-X

13. Mühlbacher AC, Bethge S. Patients' preferences: a discrete-choice experiment for treatment of non-small-cell lung cancer. Eur J Health Econ. 2015;16(6):657-670. doi:10.1007/s10198-014-0622-4

14. Bridges JF, la Cruz MD, Pavilack M, et al. Patient preferences for attributes of tyrosine kinase inhibitor treatments for EGFR mutation-positive non-small-cell lung cancer. Future Oncol. 2019;15(34):3895-3907. doi:10.2217/fon-2019-0396

15. Katz SJ, Belkora J, Elwyn G. Shared decision making for treatment of cancer: challenges and opportunities. J Oncol Pract. 2014;10 (3):206-208. doi:10.1200/JOP.2014.001434

\section{Dovepress}

states are major areas of interest for the journal. This journal has been accepted for indexing on PubMed Central. The manuscript management system is completely online and includes a very quick and fair peer-review system, which is all easy to use. Visit http:// www.dovepress.com/testimonials.php to read real quotes from published authors. 